\title{
Immunity test of the lighting installation for electromagnetic surge disturbances
}

\author{
Dorota Typańska ${ }^{1, *}$, Wojciech Machczyński ${ }^{1}$ \\ ${ }^{1}$ Poznan University of Technology, Poznan, Poland
}

\begin{abstract}
The paper presents the results of computer simulation of the operation of a lighting installation disturbed by a voltage surge of $1.2 / 50 \mu \mathrm{s}$. The components included in the model of the system were: voltage surge generator ( accordance with the PN-EN 61000-4-5 Standard), coupling - decoupling system, over-current circuit breaker, iluminance level controller and incandescent lamp. The results of simulation tests with the results of tests carried out in an accredited electromagnetic compatibility laboratory were compared.
\end{abstract}

\section{Introduction}

All electrical and electronic devices placed on the European market should be tested and certified by accredited electromagnetic compatibility laboratories. Certification of individual devices does not guarantee that a fully completed, fixed installation will be electromagnetically compatible [1, 2, 3]. Performing specialized tests of electromagnetic compatibility increases the functional safety of the devices used and improves the quality of energy in the supply networks. [4].

Due to the complexity and possible harmfulness of the installation's immunity tests to electromagnetic disturbances, it is reasonable to simulate of the system operation when the specific interfering signals are introduced. The article presents the results of computer simulation of the operation of the power regulator disturbed by lightning impulse, made in the MATLAB/Simulink software [5]. The simulation results and results of tests carried out in an accredited electromagnetic compatibility laboratory were compared.

\section{Computer simulation}

The model tests included simulation of the operation of a part of a lighting installation equipped with an overcurrent switch, a lighting power controller and an incandescent lamp with a rated power of $200 \mathrm{~W}$ supplied from a $230 \mathrm{~V}$ power grid. A $1.2 / 50 \mu$ s voltage signal disturbing the system through a coupling and decoupling system (CDN) according to PN EN 61000-4-5 Standard was supplied. Figure 1 presents a modelled circuit.

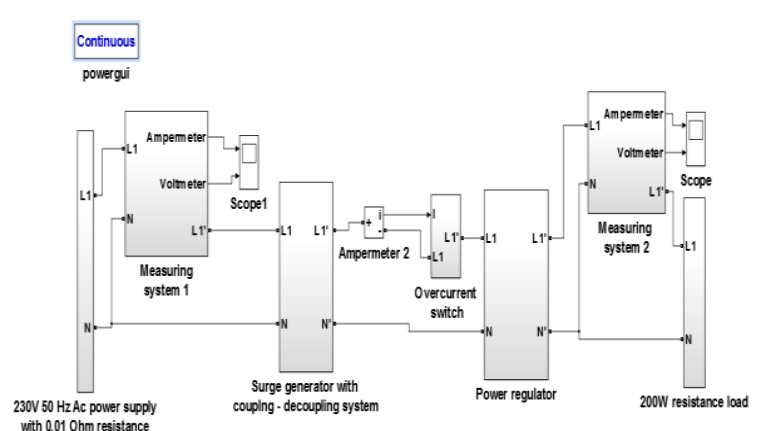

Fig. 1. Scheme of the simulated system.

On the voltage characteristic considered on the load side (measuring system 2) during the pulse disturbance, a pulse with an magnitude of $1280 \mathrm{~V}$ is visible (Fig. 2). The shape of the current waveform is coincides with the shape of the voltage. The magnitude of the current pulse resulting from the introduced disturbance is about $7.8 \mathrm{~A}$ (fig. 3).

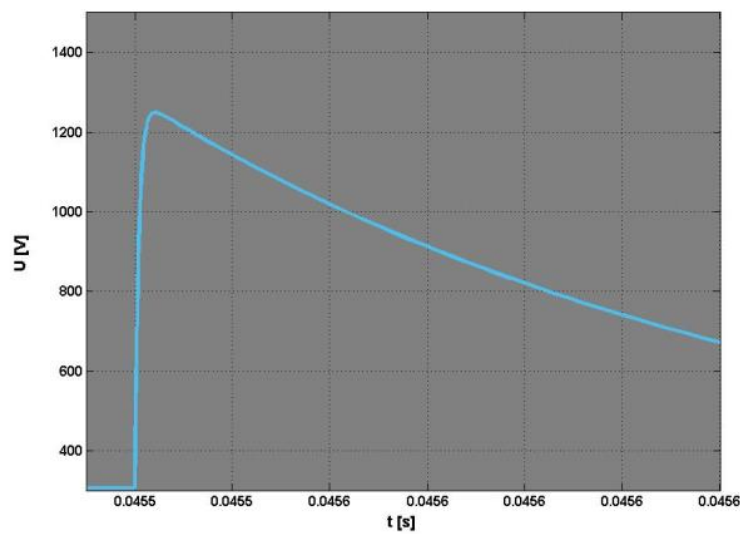

Fig. 2. The course of the voltage signal on the receiver. 


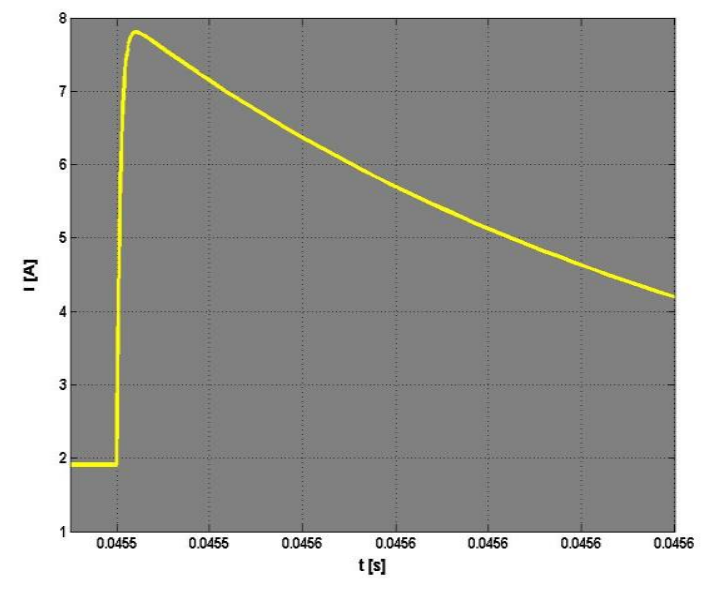

Fig. 3. The course of the current signal on the receiver.

\section{Laboratory tests}

In order to confirm the simulation tests in Matlab/Simulink software, a laboratory test stand (according to Standard [6] consisting of a power regulator limiting the intensity of light emitted by the incandescent lamp, over-current protection, surge generator 1,2 / 50 us with $\mathrm{CDN}$, and measuring system in the form of voltage and current differential probes with digital oscilloscope were prepared.

The research were carried out in an accredited electromagnetic compatibility laboratory located in the Office of Technical Inspection in Poznan. The tested system is presented in Fig. 4. The voltage accross and the current through the load were observed using an oscilloscope.

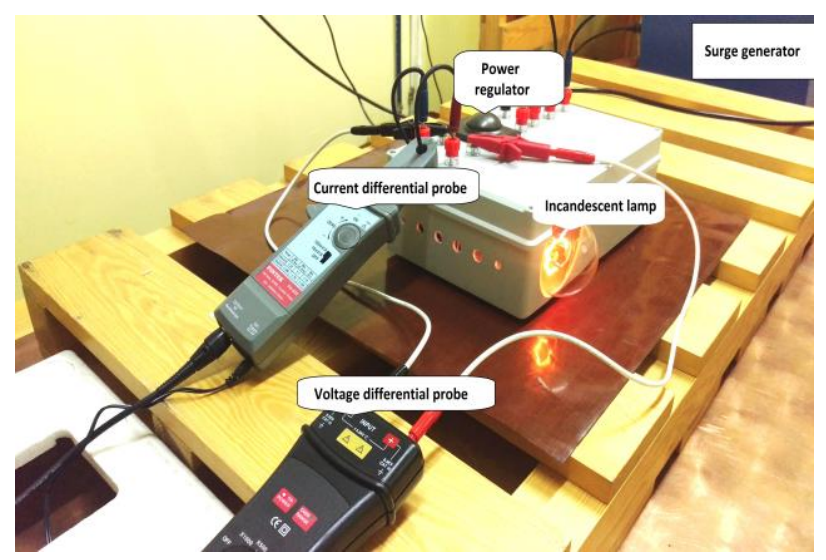

Fig. 4. Tested system.

On the voltage characteristic (Fig. 5, blue line) during the pulse disturbance, a pulse with an magnitude of $1325 \mathrm{~V}$ is visible. The shape of the current waveform (Fig. 5, yellow line) is coincides with the shape of the voltage. The magnitude of the current pulse resulting from the surge disturbance is $7.76 \mathrm{~A}$.

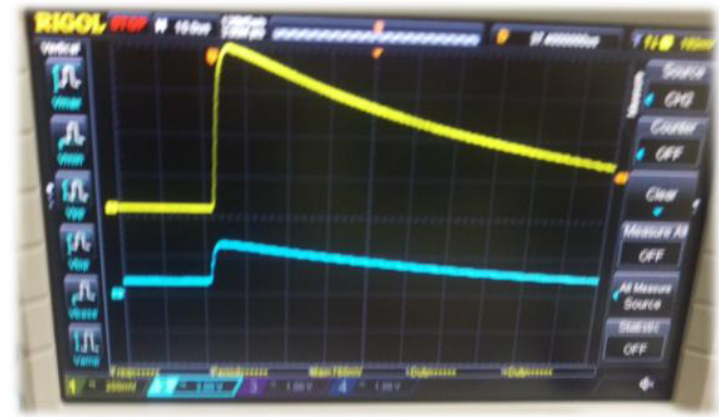

Fig. 5. The current and voltage waveform seen on the oscilloscope.

The simulated magnitude of the voltage at input of the receiver circuit due to disturbance of its operation with voltage pulse 1,2 / $50 \mu$ s, is $4 \%$ lower than voltage magnitude obtained in laboratory tests. The magnitudes of the currents in the simulated and the tested system are the same.

\section{Summary}

The current state of knowledge about disturbances occurring in electrical circuits and the causes and sources of the formation of these disturbances allows the execution of test signal model, described in the relevant general standard relating the electromagnetic compatibility testing $[7,8]$.

Preliminary results of own simulation analyzes for a selected receiver and a disturbance generator indicate the convergence of simulation results of the model of the system under consideration and laboratory tests.

\section{References}

1. D. Typańska, A. Maćkowiak, K. Sieczkarek, Prz. Elektrotech. 92/4, 38-42 (2016)

2. K. Bednarek, D. Typańska, J. Misiorny, Pozn. Univ. Technol. Acad. J. Electr. Eng. 93, 241-252 (2018)

3. D. Typańska, A. Maćkowiak, K. Sieczkarek, Prz. Elektrotech. 92/9, 243-245 (2016)

4. K. Bednarek, D. Typańska, Prz. Elektrotech. 93/12, 63-66 (2017)

5. W. Machczyński, D. Typańska, International Conference on Electromagnetic Disturbances, 63-66 (2017)

6. PN-EN 61000-4-5:2014-10 Electromagnetic compatibility (EMC) - Part 4-5: Testing and measurement techniques - Surge immunity test

7. K. Bednarek, R. Nawrowski, A. Tomczewski, Studies in Applied Electromagnetics and Mechanics 22, 363-368, (IOS Press, Amsterdam, Berlin, 2002)

8. L. Kasprzyk, A. Tomczewski, K. Bednarek, Prz. Elektrotech. 87/12b, 82-85 (2011) 